\title{
Exploratory study of Adolescents Reproductive Health Communication and their perception on reproductive health, addictions and psychological anxiety(DASS)
}

\author{
Dr. M. SRIHARI, M.A., Ph.D.Assistant Professor, Dept. of Communication and Media Studies \\ Bharathiar University, Coimbatore, India.shbharathiar@gmail.com, haricms@buc.edu.in
}

\begin{abstract}
Adolescents (10-19 years) population in India is 253 million (Census 2011), and the country needs to see them physically, mentally healthy, and socially valuable people. A significant period of transition from childhood to adulthood for biological and psychological development. A phase of puberty represents a time of dramatic transformation, and hormonal changes were the testosterone sex hormone plays an essential role in the body. In men, it's thought to regulate sex drive (libido), bone mass, fat distribution, muscle mass and strength, and the production of red blood cells and sperm [1]. Adolescents are sexually active in unique aspects exploring knowledge in diverse aspects of early life experiences. Also, developmental trauma disorder will harm their attachments, social, self-regulation skills, low self-esteem, and the development of harmful sexual behaviour. During the phase, male adolescents are addicted to drugs, which causes' Psychosocial Risks (Depression, Anxiety, Stress, and Loneliness) among adolescents, shaping one's future. The study analysis the knowledge, awareness of sexuality, masturbation, sexually transmitted infection, adolescent's sexual behaviour, information-seeking behaviour, and interpersonal communication during adolescence among arts and science University male students in Coimbatore who come from the various rural and urban backgrounds. Igniting the information-seeking action and discussion will help build a strong structure of health communication to influence individuals. The interpersonal communication between the adolescent parents and the dissemination of sex education through proper communication channels will develop a positive attitude of their body functions.
\end{abstract}

Keywords- Adolescents, Health Communication SRH, Depression, Anxiety, and Stress

\section{INTRODUCTION}

The period of transition from childhood to adulthood for biological and psychological development (10-19 years) is full of "Storm and Stress" and conflict at this developmental stage is not unusual [2]. Puberty represents a time of dramatic transformation where the testosterone sex hormone plays an essential role in male adolescents' bodies. The onset of male puberty involves enlargement of the testes at around age 11 or 12 and first ejaculation, which typically occurs between the ages of 12 and 14 . The development of secondary sexual characteristics, such as body hair and (for boys) voice changes, occurs later in puberty [3]. It becomes an essential aspect for the policymakers to invest in adolescence, so that young adults became a part of developing society. During adolescence, teens develop a more substantial recognition of their identity, including identifying a set of personal morals, ethical values, and a higher perception of feelings of self- esteem [4]. This period were health problems that will have severe consequences and could have serious adverse effects on health in the future. Adolescents worldwide face several SRH problems like unwanted pregnancy, sexually transmitted infections (STIs), and HIV infections.

Male adolescents who get disconnected from health care limit their abilities to address their health needs. The way this occurrence would be manifest and understood by boys and girls would naturally be different, as puberty is believed to intensify adherence to traditional gender roles [5]. Thus, while traditionally masculine expectations of self-reliance, emotional restraint, and social dominance might seem daunting for children to adopt at any age, they may be particularly challenging to adopt for early matures, who may already be experiencing a vulnerable and tumultuous transition [6]. 
Decisions made during adolescence, particularly regarding $\mathrm{SRH}$, have a long-term impact on human development. With the onset of puberty, young people face new challenges initiating sexual activity, entering the age of risk-taking, entering unions and making decisions on family formation [7] that affect future health and opportunities, such as the development of noncommunicable diseases (NCDs), mental disorders, and injuries. The emotional and social changes in adolescents include being preoccupied with body image, want to establish own identity, fantasy, daydreaming, rapid mood changes, emotional instability, attention-seeking behaviour, sexual attraction, curious, inquisitive nature, full of energy, restless, concrete thinking, self-exploration, and evaluation [8]. Adolescents who are sexually active and use substances have high rates of unintended pregnancy and repeat unplanned pregnancy for multiple reasons. Teens that use tobacco, alcohol, marijuana, or other drugs are more likely to be sexually active, engage in risky sexual behaviour, and experience the consequences of unsafe sex, including unintended pregnancy, compared with peers who do not use substances [9]. The adolescents are at high-risk behaviours like substance abuse, unprotected sex, unintended pregnancy, and other reproductive health issues.

The adolescent health system shares the same fundamental problems as those embedded in the organization of adult health services: the lack of communication, collaboration, and system-level planning among various private and public health services, settings, and providers [10]. As noted in the [10] report, the vast array of clinicians, hospitals, other health care facilities, insurance plans, and purchasers operate in various configurations of groups, networks, and independent practices that are collectively termed "the health care delivery system." Male adolescents do not interact with peers or get information from authentic sources about better reproductive health.

The SRH is a complete physical, mental, social well-being, and not merely the absence of disease or infirmity in all the matters relating to the reproductive system functions and processes [11]. The changes not only on the physical appearances but also associated with emotional changes, compelling sex urges. Different researchers have identified the characteristics as being related to low self-esteem in adolescents.

The feeling depressed, lacking energy, disliking one's appearance, rejecting compliments, feeling insecure or inadequate most of the time, having unrealistic expectations of oneself, having serious doubts about the future, being excessively shy, rarely expressing one's own point of view, conforming to what others want and assuming a submissive stance in most situations because consistently low self-esteem is associated with adverse outcomes, such as depression, eating disorders, delinquency, and other adjustment problems [12]. Professionals must identify youth who exhibit these characteristics help them get to adapt to the changing social environment caused by physical maturation [13]. Regardless of family form, a strong sense of bonding, closeness, and attachment to the family are associated with better emotional development, better school performance, and engagement in fewer high-risk activities, such as drug use [14]. If parental supervision and interaction with adolescents are not associated, adolescents would feel lonely, using drugs, depressive symptoms, alcohol use, and tobacco use were also significant risk factors [15].

\section{II.BACKGROUND OF THE STUDY}

\section{COMMUNICATION GAP ON REPRODUCTIVE HEALTH}

The communication gap existing between them and parents to discuss the Reproductive Health $(\mathrm{RH})$ related issues become a pivotal role in an adolescent's upbringing. The indispensable barrier that adolescents need to surpass is the communication gap existing between them and their parents, peers, and other resources. They felt shy to discuss these matters with their parents; as a result, and the friends were the only people they talked to about these issues [16]. Adolescents whose parents are more involved in their lives have significantly lower rates of "problem behaviours" such as smoking, alcohol or marijuana use, lying to parents, fighting, initiation of sexual activity, and suicidal thoughts and attempts [17]. Negativity and understanding the average growth of physiological and psychological as abnormal leads to suicidal attempts and other mental health issues.

Young people need adults who will listen to them to understand and appreciate their perspective and motivate them to use information services offered in their health [18]. Even in schools where sex education is taught, many girls and boys still feel unprepared for the puberty changes, suggesting that these important topics are not being dealt with in ways that are most useful to adolescents [19]. Young adolescent boys who are not prepared for these changes have reported feeling "somewhat perplexed" upon experiencing their first ejaculations of semen during dreaming or masturbation [20]. They have felt that something has gone wrong in their body, which has been happening only to them; most of the time, they feel ashamed, degrade themselves because of the sexual urge, and masturbation has been one of the aspects to fulfill their desire. Bodily change causes emotional stress, strain, and rapid mood swings. Hormonal changes result in thoughts about sex, irritability, restlessness, anger, and tension. Attraction to the opposite sex leads to a desire to mix freely and interact with each other. Most of the adolescents have been ignorant and kept their psychological tendency as a secret, which leads to vulnerability. 


\section{PHASE DURING ADOLESCENCE: DEPRESSION, ANXIETY, AND STRESS (DASS)}

Early maturing boys are more likely to be involved in high-risk behaviours such as sexual activity, smoking, or delinquency [21]. Policymakers have recognized depression, parents, and health professionals as a significant public health issue-individuals with chronic depression face sequel of greater severity. More frequent episodes or a longer duration of depression will affect family relationships and work performance, resulting in poor coping skills and negative traits, such as low optimism and low self-esteem [22].

Parenting style characterized by low nurturing and overprotective traits is associated with increased depression among adolescents [ 23, 24 ]. The adolescents are unlikely to seek help when adolescents do not meet their emotional needs may face various stressors, such as concerns about family relations, school performance, friendships, relationships, and financial constraints. The inability to cope with these situations' demands could increase the risk of depression, anxiety, and substance abuse [25]. Emotional development during adolescence involves establishing a realistic and coherent sense of identity in relation to others and learning to cope with stress and manage emotions [26].

A supportive environment can help adolescents negotiate this process and realize their sexual orientation [27]. An adolescent may find this awareness frightening and try to deny feelings of attraction to the same sex and to intensify feelings toward the opposite sex. As with heterosexual youth, sexual exploration proceeds with variability, depending on the individual. Most children will disclose their sexual orientation to trusted friends first but may prefer that their status remain a secret because of the stigma associated with different sexual orientation. Adolescents will engage in same-sex sexual behaviour; they may self-identify as gay, lesbian, or bisexual; they may be questioning their sexual identity or merely experimenting.

If untreated, anxiety disorders may lead to several behavioural, mental, physical complications in adolescents, such as alcohol dependence, nicotine addiction, drug abuse, suicide, and depression [28]. Temporal, emotional, behavioural disorders are associated with drug abuse, and $40 \%$ of drug addicts (opium or nonopium drugs) often show the diagnostic criteria of depression at some point in life [29]. According to the World Health Organization [30], some of the essential high-risk behaviours include smoking habits, cannabis use, consumption of fatty and low-fibre foods, physical inactivity, bullying, fighting, dangerous sexual behaviours, and alcohol consumption. Several studies have denoted the associations of depression, anxiety, and stress with specific behaviours in adolescents, such as violence (10-14), substance abuse [31] unprotected sexual intercourse, and subsequent pregnancies [32], and smoking and eating habits $[33,34]$.

Today's adolescents are more vulnerable to health implications due to their nature of experimenting and exposure to limited information regarding issues affecting their health and development [35]. The sexual and reproductive health problems faced by young people differ from one region to the other and between sexes but mainly are due to unprotected sex [36].

Ensuring access to primary health care services, including preventive health, is an essential element to care and improves the health outcomes of young people [37]. Studies on health-seeking behaviours of adolescents for STIs have shown that young people tend to delay treatment because they do not regard the symptoms of the disease as severe [38]. Low self-esteem is related to e.g., emotional problems, substance abuse, and eating [39]. They may also think about suicide more, peer-pressure describes the pressure exerted by a peer group in encouraging a person to change their attitude, behaviour, and morals. Peer pressure can also cause people to do things they wouldn't normally do, e.g., take drugs, smoke, etc.

An adolescent's sexual and reproductive health is strongly linked to their particular social, cultural, and economic environment. In addition to regional variation, experiences are diversified by age, sex, marital status, schooling, residence, migration, sexual orientation, and socioeconomic status, among other characteristics. Access to health care and sources of education, information, and support also varies widely. The variations demand country-level analyses of patterns, but despite these variations, key issues, barriers, and challenges, as well as potential solutions, can be identified across the board [40].

By and large, the barriers to use of SRH services by adolescents when categorized relate to the availability, accessibility, acceptability, and equity of health services [41]. In India, 10-37\% of adolescent students have an academic performance problem, and $34 \%$ of teenage students drop out of school. Tamil Nadu, 42.4\% [42] of adolescent students drop out from high school (Sarva Shiksha Abhiyan 2005-2006 report) [43] 34-37\% of adolescents have a negative attitude and perception to attend school [44].

Self-esteem can be defined as an individual's attitude about him or herself, involving self- evaluation along a positivenegative dimension [45]. Similarly, in developing countries, studies have shown that young people are less likely to seek professional help for more sensitive matters and turn more to friends or family members they can trust for sexual advice [46]. Socio-cultural barriers of accessing SRH services, understanding the needs, the expectations 
and preferences of young males need are of great importance to improving the health outcomes of all young people.

Adolescents today are more vulnerable to health implications due to their nature of experimenting and exposure to limited information regarding issues affecting their health and development. The process of touching or rubbing the genital with hand or anything else is known as masturbation. Some of the adolescents who want to spend their time alone in their room, practice masturbation. The study [47] has shown that 22.56 percent of teenagers have the practice of masturbation. This describes the status of masturbation practice among school adolescents of the Makawanpur district, Nepal. Studies in different parts of the world showed the prevalence of behavioural and emotional problems in adolescents in India [48]. The psychological changes are searching for personal identity, freedom, independence of thought, and action determined by their morals. Emotional development among adolescents is unstable, mood swings often with peaks of intensity, unpredictability, concerned about peer acceptance, tend to be self-conscious, lacking in selfesteem, and highly sensitive to personal criticism. They exhibit immature behaviour because their social skills frequently lag behind their mental and physical maturity. During the phase is shaping one's future male Adolescent Sexual and Reproductive Health, addictions, and Psychosocial Risks (Depression, Anxiety, Stress, and Loneliness) among Adolescents. They also do not have the appropriate skills to effectively communicate with pupils on sexual and reproductive health matters particularly the women, fear to discuss sexual issues in public, let alone with their students, and this is because sex is culturally perceived as a taboo subject which should not be addressed in society [49]. This has been the same among male adolescent who does not get the opportunity to communicate about the reproductive health among the

\section{ANALYSIS, INTERPRETATION AND DISCUSSION}

Table No. 1: The Depression, Anxiety and Stress (DASS) applied over the growth of Reproduction Organ (Penis Size/ physical Changes / Wet dreams / Masturbation / Secondary sexual organ) during the phase of puberty of Male adolescents. One Sample T test

\begin{tabular}{|c|c|c|c|c|c|c|c|c|}
\hline \multirow{2}{*}{ DASS } & \multicolumn{6}{|l|}{ Group Statistics } & \multicolumn{2}{|c|}{$\begin{array}{l}\text { Levene's Test for } \\
\text { Equality of Variances } \\
\end{array}$} \\
\hline & \multicolumn{2}{|l|}{ Place of Birth } & $\mathrm{N}$ & Mean & $\begin{array}{l}\text { Std. } \\
\text { Deviation }\end{array}$ & $\begin{array}{l}\text { Std. Error } \\
\text { Mean }\end{array}$ & $\mathrm{F}$ & Sig. \\
\hline \multirow{5}{*}{ Depression } & \multirow{2}{*}{$\begin{array}{l}\text { I couldn't seem to experience } \\
\text { any positive feeling at all }\end{array}$} & Rural & 46 & 1.5870 & 1.04512 & .15409 & \multirow[b]{2}{*}{.129} & \multirow[b]{2}{*}{.721} \\
\hline & & Urban & 29 & 1.2759 & 1.06558 & .19787 & & \\
\hline & \multirow{2}{*}{$\begin{array}{l}\text { I found it difficult to work up the } \\
\text { initiative to do things. }\end{array}$} & Rural & 46 & 1.2609 & 1.08392 & .15982 & \multirow{2}{*}{.341} & \multirow{2}{*}{.561} \\
\hline & & Urban & 29 & 1.3448 & 1.17339 & .21789 & & \\
\hline & I felt that I had nothing to look & Rural & 46 & 1.6087 & .97703 & .14406 & 7.081 & .010 \\
\hline
\end{tabular}

parents, teachers, and other in the society to discuss the common psychological and physiological issues.

\section{OBJECTIVES OF THE STUDY}

Investigate the factors of Depression, Anxiety, and Stress (DASS) during the development of physical aspects such as reproduction organs (Secondary sexual organs) and psychological issues among Adolescents.

- The study analysis the aspects of the discussion of physical and psychological changes interaction about the sexual reproductive health.

- The study analysed the level of interest and habits during the phase of adolescents.

\section{HYPOTHESES}

H01: There will be no significant influence of the development phase of the reproductive organ (puberty) in Male adolescents and on their Depression, Anxiety, and Stress (DASS).

\section{RESEARCH METHODOLOGY}

A structured self-administered questionnaire based on the level of communication during adolescence regarding sexual reproductive health was administered. Their attitude was measured using Depression, Anxiety, and Stress Scale (DASS-21). Non-Probability purposive sampling method was used for the study. Seventy-five male respondents from Bharathiar University, Coimbatore, Tamil Nadu, India were selected as samples which came from the various rural and urban background. Nonprobability purposive sampling is used in the selection of samples for the study, which covered the cross-section of adolescent boys from the University of different departments. Both open-ended and closed-ended questions were used during the survey. In-depth personal one onone interview were also conducted in the study. 


\begin{tabular}{|c|c|c|c|c|c|c|c|c|}
\hline & forward to & Urban & 29 & 1.4138 & 1.26822 & .23550 & & \\
\hline & \multirow{2}{*}{ I felt down-hearted and blue. } & Rural & 46 & 1.5000 & 1.04881 & .15464 & \multirow{2}{*}{.002} & \multirow{2}{*}{.969} \\
\hline & & Urban & 29 & 1.6552 & 1.04457 & .19397 & & \\
\hline & \multirow{2}{*}{$\begin{array}{l}\text { I was unable to become } \\
\text { enthusiastic about anything. }\end{array}$} & Rural & 46 & 1.3696 & 1.01890 & .15023 & \multirow{2}{*}{1.791} & \multirow{2}{*}{.185} \\
\hline & & Urban & 29 & 1.2414 & 1.18488 & .22003 & & \\
\hline & \multirow{2}{*}{$\begin{array}{l}\text { I felt I wasn't worth much as a } \\
\text { person }\end{array}$} & Rural & 46 & 1.4565 & 1.06888 & .15760 & \multirow{2}{*}{.030} & \multirow{2}{*}{.862} \\
\hline & & Urban & 29 & 1.3448 & 1.11085 & .20628 & & \\
\hline & \multirow{2}{*}{ I felt that life was meaningless } & Rural & 46 & 1.4565 & 1.18709 & .17503 & \multirow{2}{*}{.462} & \multirow{2}{*}{.499} \\
\hline & & Urban & 29 & 1.4483 & 1.12078 & .20812 & & \\
\hline \multirow{14}{*}{ Anxiety } & \multirow{2}{*}{$\begin{array}{l}\text { I was aware of dryness of my } \\
\text { mouth }\end{array}$} & Rural & 46 & 1.4130 & 1.00169 & .14769 & \multirow{2}{*}{.976} & \multirow{2}{*}{.327} \\
\hline & & Urban & 29 & 1.3103 & 1.13715 & .21116 & & \\
\hline & \multirow{2}{*}{$\begin{array}{l}\text { I experienced breathing } \\
\text { difficulty (e.g., excessively rapid } \\
\text { breathing, breathlessness in the } \\
\text { absence of physical exertion) }\end{array}$} & Rural & 46 & 1.2826 & 1.00362 & .14798 & \multirow[b]{2}{*}{1.009} & \multirow[b]{2}{*}{.319} \\
\hline & & Urban & 29 & 1.3448 & 1.14255 & .21217 & & \\
\hline & \multirow{2}{*}{$\begin{array}{l}\text { I experienced trembling (e.g in } \\
\text { the hands) }\end{array}$} & Rural & 46 & 1.4348 & .98098 & .14464 & \multirow{2}{*}{.993} & \multirow{2}{*}{.322} \\
\hline & & Urban & 29 & 1.6552 & 1.07822 & .20022 & & \\
\hline & \multirow{2}{*}{$\begin{array}{l}\text { I was worried about situations in } \\
\text { which I might panic and make a } \\
\text { fool of myself. }\end{array}$} & Rural & 46 & 1.5870 & 1.00169 & .14769 & \multirow{2}{*}{.791} & \multirow{2}{*}{.377} \\
\hline & & Urban & 29 & 1.7586 & .95076 & .17655 & & \\
\hline & \multirow{2}{*}{ I felt I was close to panic. } & Rural & 46 & 1.3043 & .98589 & .14536 & 044 & 834 \\
\hline & & Urban & 29 & 1.4828 & .98636 & .18316 & 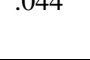 & .034 \\
\hline & I was aware of the action of my & Rural & 46 & 1.7174 & .95831 & .14130 & & \\
\hline & $\begin{array}{l}\text { exertion (e.g., sense of heart rate } \\
\text { increase, heart missing a beat). }\end{array}$ & Urban & 29 & 1.4138 & 1.01831 & .18909 & .133 & .716 \\
\hline & I felt scared without any good & Rural & 46 & 1.4565 & .91181 & .13444 & 5665 & 020 \\
\hline & reason. & Urban & 29 & 1.6552 & 1.17339 & .21789 & $5.00 J$ & 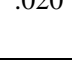 \\
\hline & I found it hard to wind down & Rural & 46 & 1.2826 & .95831 & .14130 & 542 & 464 \\
\hline & 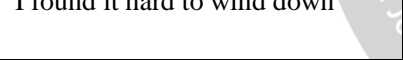 & Urban & 29 & 1.0690 & .88362 & .16408 & .042 & .404 \\
\hline & I tended to over-react to & Rural & 46 & 1.5435 & .98221 & .14482 & 005 & 042 \\
\hline & situations. & Urban & 29 & $1.7241^{A}$ & .99630 & .18501 & (005 & . 942 \\
\hline & I felt that I was using a lot of & Rural & 46 & 1.5000 & 1.09036 & .16077 & 274 & 602 \\
\hline & nervous energy & Urban & 29 & 1.6897 & 1.03866 & .19287 & $.2 / 4$ & \\
\hline Stress & If found myself oetting a oitated & Rural & 46 & 1.5000 & 1.02740 & .15148 & 238 & 627 \\
\hline Stress & 11 Iound myseli getting agitated. & Urban & 29 & 1.5172 & 1.08958 & .20233 & .238 & .021 \\
\hline & I found it difficult to relax & Rural & 46 & 1.4783 & .96007 & .14155 & 8335 & 005 \\
\hline & I found it difficult to relax. & Urban & 29 & 1.6207 & 1.26530 & .23496 & 8.335 & . \\
\hline & I was intolerant of anything that & Rural & 46 & 1.5217 & 1.02717 & .15145 & 168 & 683 \\
\hline & what I was doing. & Urban & 29 & 1.4483 & 1.08845 & .20212 & .100 & \\
\hline & I felt that I was rather touchy & Rural & 46 & 1.2826 & .95831 & .14130 & 085 & 772 \\
\hline & 1 felt that 1 was rather touchy. & Urban & 29 & 1.1724 & 1.03748 & .19265 & .085 & $.1 / 2$ \\
\hline
\end{tabular}

Table no 1 indicates that there is a high prevalence of Depression, Anxiety, and Stress during the period of adolescence. There are still many misconceptions and misbelieves regarding issues related to sexuality in adolescence among both rural and urban students. There no much mean difference in terms of depression about the growth of Reproduction Organ (Penis Size/ physical Changes / Wet dreams / Masturbation / Secondary sexual organ) during the phase of puberty of male adolescents, which should be tackled comprehensively by imparting formal puberty and sex education at a proper age. 
The finding clearly states that rural and urban boys are not aware of puberty concepts, have lesser knowledge about reproductive organs and their functions, secondary sexual characteristics, and are unaware of emotional changes. Significant values show (.020) 'they felt scared without any good reason.' The mean indicates there is no difference between rural and urban students. They had anxiety during sexual development changes and emotional changes during puberty.

Stress in youth is significantly related to anxiety, depression, and suicide [50]. The study also Indicates the rural (.96007) students are relaxed when compared to the urban (1.26530). I felt a lot of nervous energy during puberty, the adolescent's hormonal balance shifts firmly towards an adult state. Similarly, it has been reported that older adolescents are more vulnerable to stress. However, it has been suggested that this is more related to the increasing demands on the individual and improving intellectual capacity to consider an uncertain future than to age itself [50].

From the above, it indicates that both the rural and urban sectors felt intolerant of anything which causes stress, arousal, or sensations to become extreme; the adolescents engage in increased risk-taking behaviours and emotional outbursts. The most common mental health issues experienced in adolescence are stress, anxiety, and depression [51]. Such a perspective seems logical, given that many of the hormones which rise steadily throughout puberty have also been implicated in depression, social dominance, aggressive behaviour, and frustration tolerance [52]. That stress factors may increase an adolescent's vulnerability to substance abuse [53]. Males tend to show a preference for resolving conflict through external channels of expression or non-verbal behaviour (acting out, substance abuse) [54]. The depression among adolescents is persistent and has numerous negative associated features and consequences.

\section{TABLE 2: DISCUSSION OF PHYSICAL AND PSYCHOLOGICAL CHANGES DURING ADOLESCENTS}

\begin{tabular}{|c|c|c|c|c|c|c|c|c|}
\hline & & Yes & No & Total & \multicolumn{3}{|c|}{ Pearson Chi-Square } & \multirow{2}{*}{ Percentage } \\
\hline \multicolumn{4}{|l|}{ Shame (\%) } & & Value & df & Asymp. Sig. (2-sided) & \\
\hline \multirow{2}{*}{$\begin{array}{l}\text { Place } \\
\text { Birth }\end{array}$} & Rural & 71 & 28 & \multirow{2}{*}{75} & \multirow{2}{*}{$.066^{\mathrm{a}}$} & \multirow{2}{*}{1} & \multirow{2}{*}{0.797} & \multirow{2}{*}{70.7} \\
\hline & Urban & 68 & 31 & & & & & \\
\hline \multicolumn{9}{|c|}{ Culturally unacceptable } \\
\hline \multirow{2}{*}{$\begin{array}{l}\text { Place of } \\
\text { Birth }\end{array}$} & Rural & 60.8 & 39.1 & \multirow{2}{*}{75} & \multirow{2}{*}{$.506^{\mathrm{a}}$} & \multirow{2}{*}{1} & \multirow{2}{*}{0.477} & \multirow{2}{*}{64} \\
\hline & Urban & 68.9 & 31 & & & & & \\
\hline \multicolumn{9}{|c|}{ Lack of knowledge } \\
\hline \multirow{2}{*}{$\begin{array}{l}\text { Place } \\
\text { Birth }\end{array}$} & Rural & 73.9 & 26 & \multirow{2}{*}{75} & \multirow{2}{*}{$216^{\mathrm{a}}$} & & \multirow{2}{*}{0.642} & \multirow{2}{*}{72} \\
\hline & Urban & 68.9 & 31 & & & & & \\
\hline \multicolumn{9}{|c|}{ Fear of parents } \\
\hline \multirow{2}{*}{$\begin{array}{l}\text { Place } \\
\text { Birth }\end{array}$} & Rural & 56.5 & 43.4 & \multirow{2}{*}{75} & \multirow{2}{*}{$.005^{\mathrm{a}}$} & \multirow{2}{*}{1} & \multirow{2}{*}{0.944} & \multirow{2}{*}{64} \\
\hline & Urban & 75.8 & 24.13 & & & & & \\
\hline \multicolumn{9}{|c|}{ Negative Feeling } \\
\hline \multirow{2}{*}{$\begin{array}{l}\text { Place of } \\
\text { Birth }\end{array}$} & Rural & 58.6 & 41.3 & \multirow{2}{*}{75} & $000^{\mathrm{a}}$ & 1 & 0005 & 587 \\
\hline & Urban & 58.6 & 41.3 & & .000 & 1 & 0.993 & 50.1 \\
\hline Embarrassed & & & & & & & & \\
\hline Place of & Rural & 52.1 & 47.8 & 75 & & & & \\
\hline Birth & Urban & 55.1 & 44.8 & 13 & .004 & 1 & 0.0 & 53.3 \\
\hline Lack of Com & nunicati & & & & & & & \\
\hline Place & Rural & 63 & 36.9 & & $077^{\mathrm{a}}$ & & & \\
\hline Birth & Urban & 65.5 & 34.4 & 10 & .041 & 1 & 0.020 & 04 \\
\hline Excitement & & & & & & & & \\
\hline of & Rural & 45.6 & 54.3 & & & & & \\
\hline Birth & Urban & 44.8 & 55.1 & (J) & $.00 J$ & 1 & $0.94+$ & 4.0 \\
\hline
\end{tabular}


Table 2 clearly shows that rural $(60.8 \%)$ and urban $(68.9 \%)$ students felt 'ashamed', rural (60.8\%) and urban $(68.9 \%)$ 'culturally unacceptable' in talking about the normal body changes being stigmatized. Communication has not been effective in building a strong structure of health communication to influence individuals and the communities in health-related information. Health communication programs regarding adolescents seek to influence and engage the stake-holders in the communication process through various communication channels.

Rural $(73.9 \%)$ and Urban $(68.9 \%)$ Lack of knowledge becoming a sexually unhealthy adult developmental task of adolescence that requires integrating psychological, physical, cultural, spiritual, societal, and educational factors. But 'a culture of silence' often surrounds with the biological process, which has many consequences attached to this phenomenon like bodily changes and psychological issues. The taboo in the dissemination of sex education and reproductive health among adolescents has created 'embarrassment' (53.3\%), and 'negative feeling' (58.7\%) creates guilt in the psychosomatic development concerning the reproduction system. Sex education programs should be scaled up and offer accurate, comprehensive information while building skills for negotiating sexual behaviours [55].
Both the rural $(63 \%)$ and urban $(65.5 \%)$ felt there is 'Lack of Communication' for healthy adult relationships are more likely to develop when adolescent impulses are not shamed or feared. Adolescent sexuality development is both normal and positive would allow for more open communication so adolescents can be more receptive to education concerning the risks. Helping adolescents recognize all aspects of sexual development encourages them to make informed and healthy decisions about sexual matters.

Rural (58.6\%) and Urban (58.6\%) had 'negative feeling' hence healthcare workers should be equipped to provide specific, balanced sex education, including information about contraception and condoms so that young people have the means to protect themselves, contained within a context of healthy sexuality, without stigma. Adolescent should possess some knowledge about reproductive health through educational intervention is required to encourage more sensible and healthy behaviour. Fear of parents to discuss reproductive related topics, teachers' embarrassment regarding the subject, the lack of comprehensive educational materials, and social constraints on open discussion of masturbation and the reproductive health have to be overcome by the trainers and parents.

TABLE 3 : INTERACTION ABOUT THE SEXUAL REPRODUCTIVE HEALTH ISSUES

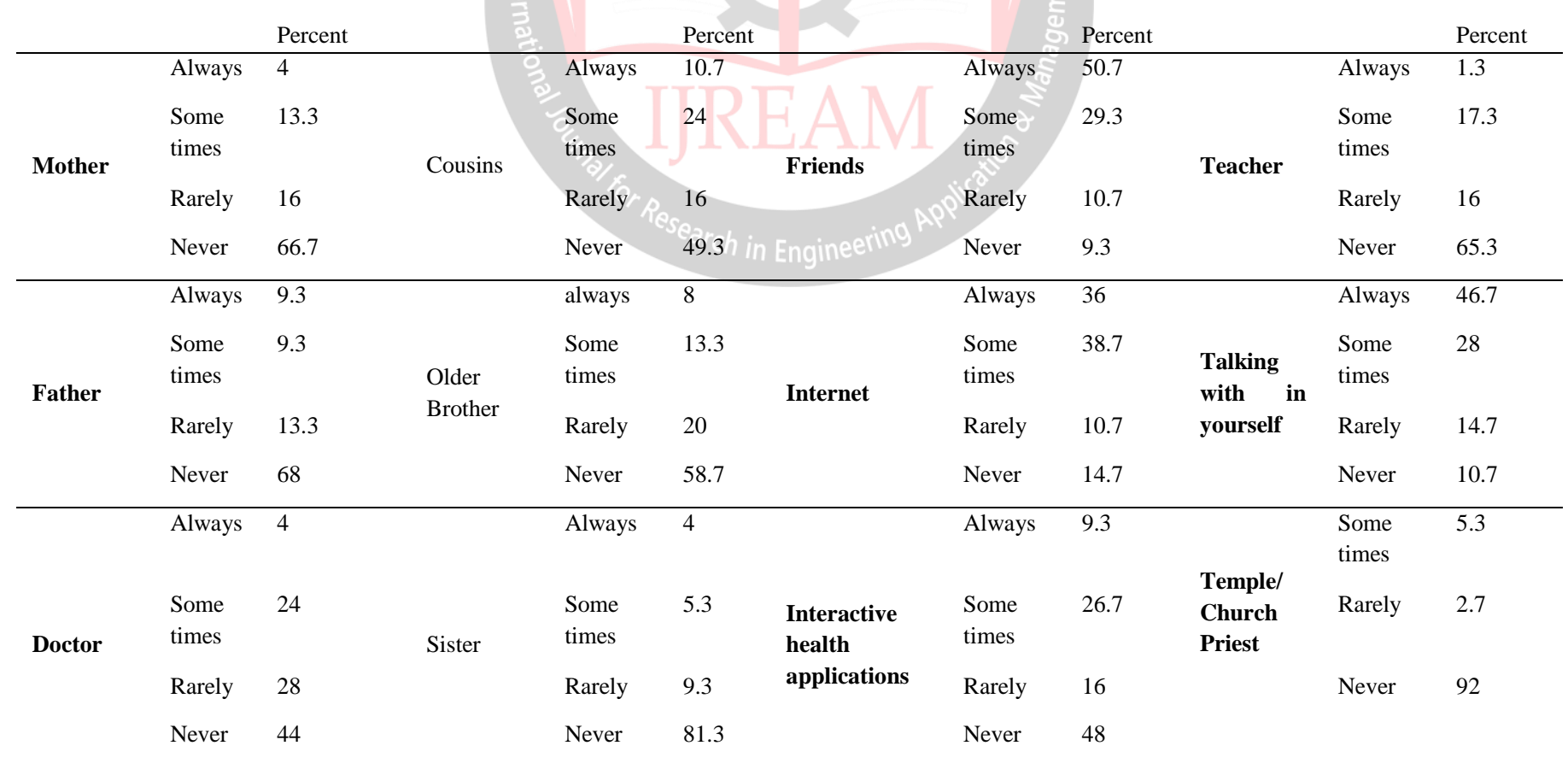

Table 3 indicates adolescent's never discussed with Mother $(66.7 \%)$, Father (68\%), Doctor (44\%), Teacher (65.3\%) about the sexual reproductive health issues. Findings of the present study further show that the source of information regarding puberty was friends $(50.7 \%)$ followed by the
Internet (36\%). They gained knowledge from friends, and the survey found rarely discussing their problems with their parents. Teenagers are understandably more comfortable talking about their issues and personal experiences with their friends. Due to a lack of 
dissemination of information through proper channels of communication, they lack interactivity and, thus, stay ignorant of their bodily functions. The absence of interpersonal communication between adolescents and their father, mother, and teachers often leads to misleading and misguiding information. The adolescent period is the time of increased psychic drive or energy associated with sexual instinct, biological maturation, and which leads to impulsiveness, low tolerance, frustration, and continuous demands for self-gratification. Effectively communicating and educating the on health practices can spread awareness among them regarding their false beliefs gaining knowledge that can build a positive attitude. Interpersonal communication between the parent's adolescents on reproductive health plays an essential role in adolescents' constructive development. Researchers have found that when teens particularly girls - talk to their parents about sexual behaviours, contraception, STIs, and pregnancy prevention (from here on, SRH discussions), they are more likely to engage in safe sexual practices, including abstinence and protective behaviours that prevent pregnancy and STIs [56]. While mothers tend to be the primary communicators with teenagers about sexual acts [57], father-teen communication is also linked to reduced risky behaviours [58].

Adolescents are unable to cope with maladaptive coping (anger and drug use), adaptive coping (seeking social support), and depression over time. Stress negatively affects psychological well-being, but it is exacerbated by depressed mood. The study indicates an increase in seeking the help of SRH issues from friends compared to other sources like parents, doctors, or online apps. This type of coping seeking social support from peers may be useful in treating troubled adolescents. When it comes long term, they need to seek professionals. Seeking social help decreases SRH issues, and the utilization of technological aspects indicates they need better communication systems where they can trust and free enough to communicate without any inhibition.

\section{TABLE 4. LEVEL OF INTEREST THEY WERE IN ADOLESCENCE}

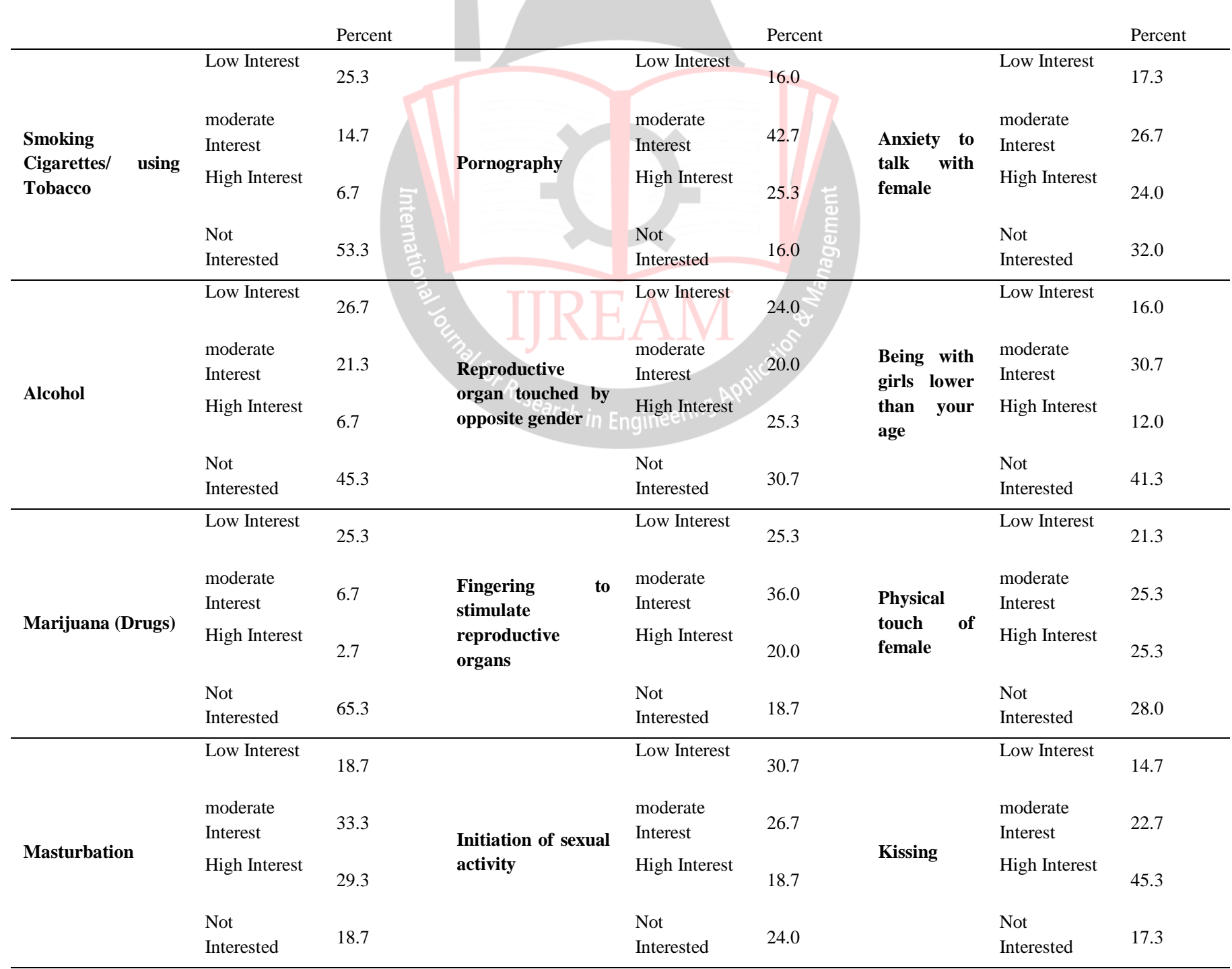


Table No 4 : Better access to information, effective communication, education, and knowledge would be a better stimulant for knowledge-seeking behaviour. Adolescents are bound to experience ignorance, false perceptions, unsafe practices regarding masturbation, and initiation of sexual activities. Analyses indicates that there is a moderate level $(42.7 \%)$ and a high level of interest $(25.3 \%)$ in watching pornography. From this perspective, Internet pornography may threaten many facets of adolescent development and well-being, mainly because "children and adolescents are widely considered the most vulnerable audiences to sexually explicit material" [59]. Pornography use is associated with increases in both selfesteem and symptoms of depression and anxiety. This finding is similar to results reported [60] found that lower antecedent life satisfaction among adolescents was associated with subsequent increases in pornography viewing over time and is consistent with self-reported motivation for pornography use to alleviate negative affective states [61]. Pornography use may contribute to personal insecurities about adolescents' bodies, appearance, or sexual performance [62] and may undermine attachment functioning, leading to relationship dysfunction and social isolation [59 ].

Cross-sectional surveys have found that pornography use is related to reports of more negative affect, poor mental health and lower quality of life among adults [63, 64] as well as lower life satisfaction and self-esteem, and more symptoms of depression among adolescents [65, 66]. The unrestrained consumption of pornography, in all its forms, can impair a person's full enjoyment of sexuality. The pressure to have a sexually satisfying life creates emotional problems. It is essential to educate campaigns beginning in schools to highlight how dark forms of desire can inhibit an unfolding of the full potential of sexuality.

It is also observed a moderate level of interest in 'fingering to stimulate reproductive organs' $(36.0 \%)$, Reproductive organ touched by opposite gender (20.0\%), and Masturbation $(33.3 \%)$ that research indicates that pornography use is either unrelated and genital satisfaction to sexual esteem. The adolescents practice masturbation as the best way of satisfying their sexual desires efficiently. The masturbation in limit may not have side effects, but excessive masturbation may cause physical, mental, social, emotional, moral, psychological problems. The joys of masturbation all reveal a steaming, teeming interior life and people restless and excited about sharing their sexual journeys and discoveries.

Also, it has been absorbed that moderate level of interest ' anxiety to talk with female' $(26.7 \%)$, 'Physical touch of female' $(25.03 \%)$, and high level of importance in 'Kissing' $(45.3 \%)$ indicates the ignorance risk causes of a variety of interrelated factors namely the demand for early marriage. Sexual relationships, access to education and employment, gender inequality, sexual violence, and the influence of mass media and lifestyle. Due to a high level of interest in 'pornography' and 'masturbation,' they will try to avoid marriage life and be less interested in sexual unification aspects of experience with the opposite gender. "Sexless marriage" would create more stress in satisfaction in marriage life, which will lead to high fertility issues and divorce in family life.

\section{CONCLUSION}

Reproductive health education needs to improve students' knowledge and attitudes about sexuality and decisionmaking related to the students' plans. The high prevalence of depression underscores the need to understand the psychosocial experiences and consequences of depression . Which reciprocal relationships to prevent further selfdestruction among youth about reproductive sexual health. The depression, anxiety, and stress among the students were found to be quite high. Hence depression in this population is associated with increased risk of suicidal behaviour, homicidal ideation, tobacco use, and other substance abuse into adulthood [67]. If elementary students have a better understanding of reproductive health, sexuality, and gender, upcoming younger generations would understand the risks of unsafe sex and unmet-need. The Cairo International Conference on Population and Development (ICPD) Programme of Action (1994) [68], urged: "... special efforts should be made to emphasize men's shared responsibility and promote their active involvement in responsible parenthood, sexual and reproductive behaviour including family planning; prenatal, maternal child health; prevention of sexually transmitted diseases, including HIV; prevention of unwanted and high-risk pregnancies; shared control and contribution to family income, children's education, health, and nutrition; recognition and promotion of equal value of children of both sexes. Male responsibilities in family life must be included in the education of children from the earliest ages. Special emphasis should be placed on the prevention of violence against women and children".

The physically and emotionally healthy group has significant health care issues involving puberty, sexual health, risk behaviours, substance use, and mental health. An essential tool for connecting with the adolescent male by far is excellent communication. Mainstream media and other communication channels have exposed the reproductive organ's sexuality and reproduction to fulfil their desires. Appropriate notification should be provided to increase people's participation in development and inform, motivate, and train the population on reproductive health, which is an essential area of concern in adolescent health. The boy's reaction to puberty greatly influences reproductive health, his beliefs and attitude towards masturbation, smoking, alcohol, initiation of sexual 
activity, and, more important, his behaviour during it. Masturbation is always considered a barrier and taboo, which became a reason for people to avoid talking and to avoid having open discussions. Masturbation is also viewed as an embarrassment in many cultures that it develops a negative attitude. Communication media such as television, radio, and other audio-visual aids indirectly have not exposed the concept of reproductive health to the public has been less informative and makes 'shy and embarrassing' across the country. Adolescents lack the necessary knowledge on reproductive health mainly because they are too reluctant to discuss these topics with their parents and feel hesitant to seek help regarding their physical and psychological disorders and problems, thus developing a negative attitude.

Adolescent self-efficacy is a significant factor for developing a positive attitude and ability to overcome all the barriers around reproductive health, which will eventually motivate them to experience their adolescent life with happiness and security. Teachers should break the inhibition of feeling shy and embarrassed to counsel the boys regarding health practices. Media should play a role in educating in an informative manner instead of giving them an awkward feeling. It is essential to pass on useful information through print and visual media to become aware of safe practices. The policymakers, curriculum development center, parents, teachers, and other concerned organizations should be responsible for protecting adolescents.

It is also observed level of interest in 'fingering to stimulate reproductive organs,' reproductive organ touched by the opposite gender, and masturbation, despite its apparent widespread prevalence, masturbation is a highly stigmatized topic viewed negatively across settings. Improved understanding of masturbation is critical to a comprehensive understanding of healthy adolescent sexual development. Masturbation with other sexual behaviours indicates that masturbation is an essential component of adolescent sexuality rather than an isolated or transient phenomenon.

Adolescent's DASS needs to be addressed through communication factors on sexual reproductive health and is to be developed as an effective means of helping adolescents cope with their newfound skill demand more productively. Sexuality education will thus allow children to gain knowledge about the most effective ways of sexual abuse. Skills learned through sexuality education will prepare children to recognize potentially inappropriate behaviour and understand the different emotions that come with feeling unsafe, verbalizing abuse to seek help from adults, and promptly disclosing them. "Igniting the information-seeking behaviour and communication" will help build a strong structure of health communication to influence individuals."

\section{REFERENCES}

[1] National Institutes of Health Understanding How Testosterone Affects Men (2013)

https://www.nih.gov/news-events/nih-researchmatters/understanding-how-testosterone-affects-men

[2] Stanley (1904) in Saba Hashmi Adolescence: An Age of Storm and Stress Review of Arts and Humanities, Vol. 2 No. 1, June $2013 \quad$ https://rahnet.com/journals/rah/Vol_2_No_1_June_2013/2.pdf

[3] Archibald, Graber, \& Brooks-Gunn, (1999); Marshall \& Tanner, (1969, 1970) in Developing Adolescents: A Reference for Professionals (2002), Copyright (C2002 by the American Psychological Association. 750 First Street, NE Washington, DC 20002-4242

[4] Stang, J., \& Story, M., ADOLESCENT GROWTH AND DEVELOPMENT, (2005) http://demoiselle2femme.org/wpcontent/uploads/Adolescent-Growth-and-Development.pdf

[5] Galambos NL, Almeida DM, Petersen AC. Masculinity, femininity, and sex role attitudes in early adolescence: Exploring gender intensification. Child Development. 1990;61:1905-1914 in Adolescent Gender-Role Identity and Mental Health: Gender Intensification Revisited Heather A. Priess, Sara M. Lindberg, and Janet Shibley Hyde, https://www.ncbi.nlm.nih.gov/pmc/articles/PMC4244905/ available in PMC 2014 Nov 26.

[6] Jane Mendle and Joseph Ferrero, Detrimental psychological outcomes associated with pubertal timing in adolescent boys, journal homepage: www.elsevier.com/locate/dr 2011 Elsevier Inc. All rights reserved.https://cpb-use1.wpmucdn.com/blogs.cornell.edu/dist/0/2281/files/2012/08/Me ndle-Ferrero-2012-zw5p6n.pdf

[7] WDR, (2007); WDR ( 2012) in Rafael Cortez, Meaghen Quinlan-Davidson, and Seemeen Saadat October (2014) Challenges for adolescent's sexual and reproductive health within the context of universal health coverage, World Bank Group, Health, Nutrition and Population Global Practice http://documents.worldbank.org/curated/en/53937146832670128 0/pdf/912920BRI0Chal00Box385330B00PUBLIC0.pdf

[8] Stang, J., \& Story, M., (2005) in Shodhganagahttps://shodhganga.inflibnet.ac.in/bitstream/10603/1 7935/20/09_chapter\%201.pdf

[9] Adolescent substance use: America's \#1 public health problem. The National Center on Addiction and Substance Abuse at Columbia University; 2011. http://www.casacolumbia.org/upload/2011/20110629adole scentsubstanceuse.pdf.

[10] Institute of Medicine. (2003). The Future of the Public's Health in the 21st Century. Washington, DC: The National Academies Press.

[11] WHO (1975) in Introduction to reproductive health and the environment, Children's Environmental Health Public Health and the Environment World Health Organization www.who.int/ceh https://www.who.int/ceh/capacity/introduction_reproductive.pdf? ua $=1$

[12] Jaffe, M. L.. In Developing Adolescents: A Reference for Professionals, In Adolescence. New York: Wiley (1998) https://www.apa.org/pi/families/resources/develop.pdf 
[13] Harter, S., \& Marold, D. B.. Psychosocial risk factors contributing to adolescent suicide ideation.(1992) In G. Noam \& S. Borst (Eds.), Child and adolescent suicide. San Francisco: Jossey-Bass.

[14] Resnick, M. D., Bearman, P. S., Blum, R. W., Bauman, K. E., Harris, K. M., Jones, J., Tabor, J., Beuhring, T., Sieving, R. E., Shew, M., Ireland, M., Bearinger, L. H., \&Udry, J. R. (1997). Protecting adolescents from harm: Findings from the National Longitudinal Study on Adolescent Health. Journal of the American Medical Association, 278, 823-832.

[15] Jane Mendle and Joseph Ferrero Detrimental psychological outcomes associated with pubertal timing in adolescent boys, journal homepage: www.elsevier.com/locate/dr 2011 Elsevier Inc. https://cpb-use1.wpmucdn.com/blogs.cornell.edu/dist/0/2281/files/2012/08/Me ndle-Ferrero-2012-zw5p6n.pdf

[16] Jejeebhoy, S. J and K. G. Santhya. Parent-child communication on sexual and reproductive health matters: Perspectives of mothers and fathers of youth in India. (2011) New Delhi: Population Council.

[17 ] U.S. Council of Economic Advisers (2000). Teens and their parents in the 21st century: An examination of trends in teen behavior and the role of parental involvement. Washington, DC: White House

[18] Hamburg, D. A. Toward a strategy for healthy adolescent development. American Journal of Psychiatry, (1997). 154, 7-12.

[19] Coleman, J. C., \& Hendry, L. B.. The nature of adolescence (3rd ed.). (1999)New York: Routledge.

[20] Stein, J. H., \& Reiser, L. W. A study of White middle-class adolescent boys' responses to "semenarche" (the first ejaculation). (1994)Journal of Youth and Adolescence, 23, 373384

[21] Flannery, D. J., Rowe, D. C., \& Gulley, B. L. Impact of pubertal status, timing, and age on adolescent sexual experience and delinquency.(1993). Journal of Adolescent Research, 8, 2140

[22] Institute for Public Health, Ministry of Health Malaysia, Kuala Lumpur, Malaysia in Prevalence and Correlates of Depression Among Adolescents in Malaysia (2014) in AsiaPacific Journal of Public Health · July 2014

[23] Betts J, Gullone E, Allen JS, An examination of emotion regulation, temperament, and parenting style as potential predictors of adolescent depression risk status: A correlational study, British Journal of Developmental Psychology (2009), 27, 473-485 q 2009 The British Psychological Society

[24] Vogel JS, Hurford DP, Smith JV, Cole A. (2003) in NorhafizahBte Sahril1,et al (2019) Depression Severity and its Associated Factors among School-Going Adolescents in Malaysia, Journal of Depression and Anxiety, Journal of Depression and Anxietyhttps://www.longdom.org/openaccess/depression-severity-and-its-associated-factors-amongschoolgoing-adolescents-in-malaysia.pdf

[25] Einar B. Thorsteinsson, Stephanie Mariee Ryan, Sigrun Sveinbjornsdottir (2013) The Mediating Effects of Social Support and Coping on the Stress-Depression Relationship in Rural and Urban Adolescents, Open Journal of Depression 2013. Vol.2, No.1, 1-6 Published Online February 2013 in SciRes(http://www.scirp.org/journal/ojd) https://www.scirp.org/pdf/OJD_2013022511371535.pdf
[26] Santrock, J. W. Adolescence (8th ed.). New York: McGrawHill. In Developing Adolescents: A Reference for Professionals, (2001) AMERICAN PSYCHOLOGICAL ASSOCIATION https://www.apa.org/pi/families/resources/develop.pdf

[27] Ryan, C., \& Futterman, D.. Lesbian and gay youth: Care and counseling. New York: Columbia University Press (1998). http://howyouthlearn.org/pdf/Adolescent\%20Development.PDF

[28] Mahmoud J.S.R, Staten R.T, Hall L.A, LennieT.A. The relationship among young adult college students' depression, anxiety, stress, demographic, life satisfaction and coping styles. Issues Ment Health Nurs. 2012 Mar; 33(3):149-56.).

[29] Jafar Anisi,1 Mohammad Hossein Bahadori,1,* and Marziyeh Jahanbakhsh( 2013) (eveloping and Validation of Identifying People in Risk of Addiction, Int J High Risk Behav Addictv.1(4); Winter 2013 PMC4070132 https://www.ncbi.nlm.nih.gov/pmc/articles/PMC4070132/

[30] World health organization (2004) Young people's health in context: selected key findings from the health behavior in schoolaged Children study. Copenhagen, edinburgh, , 3 June

[31] VAN Rooij AJ, Kuss DJ, Griffiths MD, Shorter GW, Schoenmakers MT, VAN DE Mheen D. 2014 The (co-) occurrence of problematic video gaming, substance use, and psychosocial problems in adolescents. J Behav Addict. Sep; 3(3):157-65.

[32] Shrier LA, Harris SK, Sternberg M, Beardslee WR. (2001) Associations of depression, self-esteem, and substance use with sexual risk amongadolescents. Prev Med. 2001 Sep; 33(3):17989.

[33] Goodman E, Capitman J. Depressive symptoms and cigarette smoking among teens, Pediatrics. 2000 Oct; 106(4):74855.

[34] Tomori M, Rus-Makovec M. Eating behavior, depression and self-esteem in high school students. J Adolesc Health. 2000 May; 26(5):361-7

[35] Stang, J., \& Story, M., (2005) in Shodhganagahttps://shodhganga.inflibnet.ac.in/bitstream/10603/1 92570/4/chapter\%201.pdf

[36] L. Bearinger, R. Sieving, V. SharmaGlobal perspectives on the sexual and reproductive health of adolescent: patterns, prevention, and potential The Lancet, 369 (9568) (2007), pp. $1220-1231$

[37] Andre Tylee 1, Dagmar M Haller 2, Tanya Graham 3, Rachel Churchill 3, Lena A Sanci 42007 , Youthfriendly Primary-Care Services: How Are We Doing and What More Needs to Be Done?, May 5;369(9572):1565-1573. doi: 10.1016/S0140-6736(07)60371-7.

[38] Mmari KN, Oseni O, Fatusi AO. STI treatment-seeking behaviors among youth in Nigeria: are there gender differences? Int Perspect Sex Reprod Health. 2010;36:72-9.

[39] Leary MR, Schreindorfer LS, Haupt AL. The role of low self-esteem in emotional and behavioral problems: why is low self-esteem dysfunctional. J Soc Clin Psychol. 1995;14(3):297314.doi: 10.1521/jscp.1995.14.3.297.

[40] Jessica L.Morris and HamidRushwan (2015) Adolescent sexual and reproductive health: The global challenges, International Journal of Gynecology \& Obstetrics, https://doi.org/10.1016/j.ijgo.2015.02.006 
[41] World Health Organziation (WHO) Making health services adolescent friendly: Developing national quality standards for adolescent-friendly health services. Geneva, Switzerland: Department of Maternal, Newborn, Child and Adolescent Health; 2012. http://apps.who.int/iris/bitstream/10665/75217/1/97892415 03594_eng.pdf.

[42] B Maithly, Vartika Saxena (2008) Adolescent's educational status and reasons for dropout from the school, Rural Development Institute, Himalayan Institute of Medical Sciences, Doiwala, Dehradun, India [43] (Sarva Shiksha Abhiyan 2005-2006 report) in https://shodhganga.inflibnet.ac.in/bitstream/10603/17935/20/09_ chapter\%201.pdf

[44](IIPS, Mumbai and Population Council, New Delhi 2010) in https://shodhganga.inflibnet.ac.in/bitstream/10603/17935/20/09_ chapter\%201.pdf

[45] Baron, R. A., \& Byrne, D. (1991). Social Psychology: u nderstanding $\mathrm{h}$ uman interactions. (6th Ed.). Boston, MA: Allyn\& Bacon

[46] Erulkar, A. S., C. J. Onoka, A. Phiri (2005): "What is youthfriendly? Adolescents' preferences for reproductive health services in Kenya and Zimbabwe.”, in: African journal of reproductive health, Vol. 9(3), pp. 51-58.

[47] Prajapati et al (2011): A study of nutritional status and high risk behavior of adolescents in Ahmedabad: A cross sectional study, Healthline Volume 2 issue 1, Jan- Jun 2011.

[48] Pathak Rambha, Sharma RC, Parvan UC et al. Behavioural and emotional problems in school going adolescents. Australas Med J 2011; 4(1): 15-21

[49] Mitchell K (2000) Adolescent Sexual and Reproductive Health: Tool kit for Humanitarian Settings. A Companion to the Inter-Agency Field Manual on Reproductive Health in Humanitarian Settings; September 2009

[50] D.G.ByrneaS.C.DavenportaJ.Mazanovb (2007) Profiles of adolescent stress: The development of the adolescent stress questionnaire (ASQ) Journal of Adolescence, Volume 30, Issue 3, June 2007, Pages 393416https://www.sciencedirect.com/science/article/abs/pii/S01401 97106000303

[51] Cummings, C. M., Caporino, N. E., \& Kendall, P. C. (2014). Comorbidity of anxiety and depression in children and adolescents: 20 years after. Psychological Bulletin, 140(3), 816845.

[52] Richard Rowe, Barbara Maughan, Carol M. Worthman, E. Jane Costello, and Adrian Angold (2004) Testosterone, Antisocial Behavior, and Social Dominance in Boys: Pubertal Development and Biosocial Interaction, BIOL PSYCHIATRY 2004;55:546-552, 2004 Society of Biological Psychiatry

[53] Sussman S, Earleywine M, Wills T, Cody C, Biglan T, Dent $\mathrm{CW}$, Newcomb MD. The motivation, skills, and decision-making model of "drug abuse" prevention. Subst Use Misuse. 2004;39:1971-2016.

[54] Copeland, E. P., \& Hess, R. S. (1995). Differences in young adolescents' coping strategies based on gender and ethnicity. The Journal of Early Adolescence, 15, 203-219.

[55] .H. Bearinger, R.E. Sieving, J. Ferguson, V. Sharma Global perspectives on the sexual and reproductive health of adolescents: patterns, prevention, and potential Lancet, 369 (9568) (2007), pp. 1220-1231,
https://www.sciencedirect.com/science/article/abs/pii/S01406736 07603675

[56] Widman L., Choukas-Bradley S., Noar S.M., Nesi J., Garrett K. Parent-adolescent sexual communication and adolescent safer sex behavior: A meta-analysis. JAMA Pediatr. 2016;170:52-61. doi: 10.1001/jamapediatrics.2015.2731

[57] Wikkeling-Scott L.F. Dr.P.H. Thesis. Morgan State University; Baltimore, MD, USA: 2011. An Examination of the Influence of Mother-Child Communication and Maternal Monitoring on Sexual Behavior in African American High School Students.

[58] Vincent Guilamo-Ramos, PhD, MPH, LCSW, $\triangle^{\mathrm{a}, \mathrm{b}}$ Alida Bouris, PhD, ${ }^{\mathrm{c} J a n e}$ Lee, MSW, ${ }^{\mathrm{b}}$ Katharine McCarthy, MPH, ${ }^{\mathrm{b}}$ Shannon L. Michael, $\mathrm{PhD},{ }^{\mathrm{d}}$ Seraphine Pitt-Barnes, $\mathrm{PhD}^{\mathrm{d}}$ and Patricia Dittus, $\mathrm{PhD}^{\mathrm{d}}$ (. 2012 ) Paternal Influences on Adolescent Sexual Risk Behaviors: A Structured Literature ReviewPediatrics. 2012 Nov; 130(5): e1313e1325.doi: $10.1542 /$ peds.2011-

2066https://www.ncbi.nlm.nih.gov/pmc/articles/PMC5527663/

[59] Owens EW, Behun RJ, Manning JC, Reid RC. The Impact of Internet Pornography on Adolescents: A Review of the Research. Sex Addict Compulsivity. 2012;19: 99-122. 10.1080/10720162.2012.660431

[60] Peter J, Valkenburg PM. The use of sexually explicit internet material and its antecedents: A longitudinal comparison of adolescents and adults. Arch Sex Behav. 2011;40: 1015-1025. 10.1007/s10508-010-9644-x [PMC free article] [PubMed] [CrossRef] [Google Scholar]

[61] Perse EM. Uses of Erotica and Acceptance of Rape Myths. Communic Res. 1994;21: 488-515. 10.1177/009365094021004003

[62] Collins RL, Strasburger VC, Brown JD, Donnerstein E, Lenhart A, Ward LM. Sexual Media and Childhood Well-being and Health. Pediatrics. 2017;140: S162-S166. 10.1542/peds.2016-1758X [PubMed] [CrossRef] [Google Scholar]

[63]Tylka TL. No harm in looking, right? Men's pornography consumption, body image, and well-being. Psychol Men Masculinity. 2015;16: 97-107. 10.1037/a0035774

[64] Weaver JB, Weaver SS, Mays D, Hopkins GL, Kannenberg W, MCBride D. Mental- and physical-health indicators and sexually explicit media use behavior by adults. J Sex Med. 2011;8: 764-772. 10.1111/j.1743-6109.2010.02030.

[65] Kim Y-H. Adolescents ' Health Behaviours and Its Associations With Psychological Variables. Cent Eur J Public Health. 2011;19: 205-209.

[66] Kim Y-H. Korean adolescents' health risk behaviors and their relationships with the selected psychological constructs. J Adolesc Heal. 2001;29: 298-306. 10.1016/s1054139x(01)00218-x

[68] John T, Cherian A. Depressive disorders in the child and adolescent population [editorial]. Indian Pediatr 2001;38: 12111216

[67] UNFPA, Population and development, programme of action adopted at the International Conference on Population and Development (ICPD), Cairo, 5-13 September 1994 Volume 1. New York, United Nations, 199. 